\title{
Saccharomyces Cerevisiae Used As Probiotic: Strains Characterization And Cell Viability
}

\author{
Keila M. R. Duarte ${ }^{1}$, Luiz H. Gomes ${ }^{2}$, Ana C. K. Sampaio ${ }^{3}$; J. Issakowicz ${ }_{1}^{3}$, \\ Flavio Rocha, Thiago P. Granato , Suleize R. Terra \\ ${ }^{1}$ CPDNAP - Institute of Animal Science and Pastures-Rua Heitor Penteado, 56 Nova Odessa, SP Brazil. \\ 13460-000, \\ ${ }^{2}$ USP- ESALQ- Environmental Chemistry Lab, Av. Pádua Dias 11, Piracicaba, SP Brazil,13418-900 \\ ${ }^{3}$-USP CENA-Nutrition Lab, Av. Centenário, 606 Piracicaba, SP Brazil
}

\begin{abstract}
The assay aimed to evaluate the cell viability of commercial yeast strains for bakery purpose in comparison to a selected strain (Yea-Sacc ${ }^{\circledR 026}$, Alltech $\left.{ }^{\circledR}\right)$ indicated as a probiotic to be added to animal feed, promising yield gains. The objective of this first study was to check the number of viable cells, once the indicated product to be classified as probiotic needs to provide live cells. We tested the viability of one commercial probiotic strain (Yea-Sacc ${ }^{1026}$ ) in comparison to four bakery commercial yeast. Our results showed a low viability of the probiotic Saccharomyces cerevisiae, which was $7.7 \%$ and the bakery yeasts around $35 \%$ of viable cells. The sustainability calls for alternative sources for animal feeding and the use of microorganisms is very welcome in the livestock chain, provided that the product presented has the characteristics inherent to it.
\end{abstract}

Keywords: animal diet, livestock improvement, yeast

\section{Introduction}

Probiotics are defined as live microorganisms with a positive effect on the host, once ingested. Such microorganisms are being studied for decades and due to the high resistance to anti-micro biotic substances they are used as alternative treatments for gastrointestinal disorders or its prevention. Nowadays, major species used are Saccharomyces boulardii and S. cerevisiae yeasts. Due to the risk of antibiotic use in large amounts and excessive doses, several laboratories and research centers are investing on probiotic, stimulated by the WHO (World Health organization). Recently a research showed a S. cerevisiae strain isolated from sugar-cane cachaça was effective on the mice protection against challenge tests with intestinal pathogens [1]. França and Rigo [2] related a wide range of live yeast used as probiotic additives in the control of rumen standards, used on evaluation of ruminants nutrition, area which S. cerevisiae is the major product used for the last 60 years favoring animal digestion.

Other authors [3] presented results on using live yeast as additives on animal nutrition, market that triplicates on the last 10 years in the USA. Once the yeast cells are not a natural host, yeast cells do not adhere to the intestine epithelium are carried over the gastrointestinal tract with the bolus, decreasing the pressure exercised by pathogenic microorganisms present [4].

Therefore, not all commercialized products have all characteristics needed to be used as therapeutic alternative: minimum number of viable cells; ability to be storage and reactivated, essential conditions for a good effect as probiotic on gastrointestinal tract [5]. The loss of viability on microorganisms populations, presented as additives in commercial food are related to physical conditions as $\mathrm{pH}$, temperature, osmotic pressure, applied to the food conservation procedures [6,7].

In this work, we used a commercial probiotic Saccharomyces cerevisiae Yea-Sacc ${ }^{1026}$ (Alltech ${ }^{\circledR}$ ) characterized as a live culture of S. cerevisiae, 1026 strain, authorized by the European Union (EC No. 886/2009) as additives for horse nutrition in comparison to four bakery yeast commonly commercialized.

\section{MATERIAL AND METHODS}

The yeast strains used were lyophilized commercial yeast for bakery Commercial brands: Pamix, Fleischmann, Dr. Oetker and fresh yeast brand Mauri in comparison to Yea-Sacc ${ }^{1026}$. Yeast cells dilutions were done on saline buffer $(0.85 \% \mathrm{NaCl})$ sterilized and the samples received viability dye methylene blue solution and rest for 5 minutes. One drop was placed into a Neubauer Chamber and the viable cells were counted, as shown on figure 1. Viable cells turn out blue. Dead yeast cells - white or transparent. All strains were counted in three replicates. 


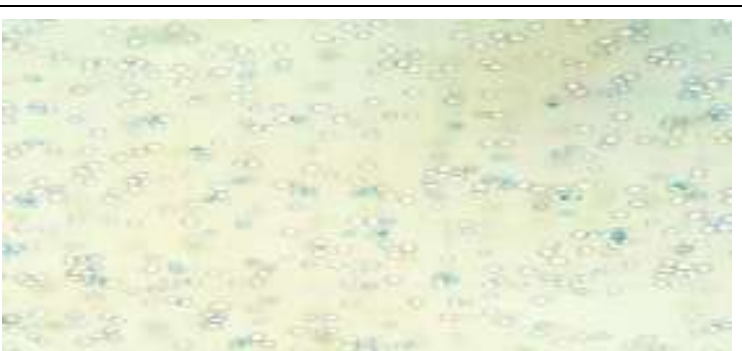

Figure 1. S. cerevisiae view at an optical microscope, $40 \mathrm{X}$ increased. White cells: non-viable; Blue cells: viable or live cells.

The commercial yeast (Yea-Sacc ${ }^{1026}$ ) was submitted to serial dillutions and inoculated in YEPD solid medium. Petri dishes were kept at $28{ }^{\circ} \mathrm{C}$ and the colonies counting was done.

\section{RESULTS AND DISCUSSION}

The viability cells test, based upon blue dying of viable cells is presented on table 1 , showing the percentage of live cells counted, for each $S$. cevevisiae strain used.

Table 1. Viable cells identified by methylene blue dye procedure. All tested Saccharomyces are commercial brands for bakery purpose, except Yea-Sacc ${ }^{1026}$

\begin{tabular}{lccc}
\hline Yeast & non-viable cells & live cells & viability\% \\
\hline Yea Sacc 1026 & $6,0 \times 10^{8}$ & $5,0 \times 10^{7}$ & 7,69 \\
Pamix & $1,2 \times 10^{9}$ & $1,4 \times 10^{9}$ & 53,84 \\
Fleischmann & $4,8 \times 10^{7}$ & $2,1 \times 10^{7}$ & 30,43 \\
Dr. Oetker & $3,1 \times 10^{7}$ & $2,1 \times 10^{7}$ & 40,38 \\
Mauri & $8,9 \times 10^{7}$ & $1,2 \times 10^{7}$ & 13,19 \\
\hline
\end{tabular}

The commercial yeast sold as probiotic show lowest cell viability in comparison to bakery yeast. Similar results were obtained by MARTINS et al.[5], using yeast from alcohol industry in comparison to a probiotic used in the livestock market. Inoculation in YEPD, an specific media for yeast was done to assure the low viability of the commercial probiotic. The growth on specific media presented a total count of $9.3 \times 10^{5}$ UCF (Unit colony forming), lower than the commercial label for probiotic product and besides that, showed more than one specie growing, with very different visual morphology.

With such results, we cannot assure the efficiency of Saccharomyces cerevisiae in livestock feeding; once the probiotic needs to be "alive" and the introduction of $S$. cerevisiae dead cells can also increase the production once yeast offers protein and micronutrients to enrich the food [8]. Arcos-Garcia et al.[9] published the inconsistence on the data collected due to the interactions between yeasts and forage offered to animals. These authors also showed the addition of two commercial probiotic Saccharomyces cerevisiae (Yea-Sacc ${ }^{1026}$ and Levucell) did not improve the digestibility or fermentation process in the animal's diet.

Yanbo and Zirong [10] reported the survival, weight gain and nutrient use for some animals supplemented with probiotics showed results dependent on the probiotic used.

For fishery and sea food, research suggest the inclusion of live microorganisms as Saccharomyces cerevisiae on the feed formulation, improving the performance and nutrient use on the diet [11] therefore, to assure such information, the viability of added cells must be evaluated.

Abdel-Tawwab [12] evaluated Nile tilapia (Oreochromis niloticus) and observed the physiological variables were directed affected by the diet. Feed with protein levels more than $45 \%$ and yeast added $\left(2.0 \mathrm{~g} \mathrm{Kg}^{-1}\right.$ ), better were the fish yield and decreased the mortality rate. Other groups working with pigs [13] reported the addition of $0.3 \%$ of yeast extract presented as probiotic additive on the diet. Among all probiotic used, $S$. cerevisiae showed less colonies growth in comparison to other yeast species, contradicting some papers.

\section{Conclusions}

The commercial yeast (Yea-Sacc ${ }^{1026}$ ) presented as probiotic showed lower viability in comparison to commercial bakery yeasts. Therefore, the simple addition of yeast, dead or live, contributes to animal performance, bringing Complex B vitamins, selenium and other micronutrients. In this case, yeast should be presented as pre-biotic or a supplement to diet and not as a probiotic product. 
To CAPES, for the scholarship.

\section{Acknowledgements}

\section{References}

F.S. Martins, Screening of yeast as probiotic based on capacities to colonize the gastrointestinal tract and to protect against enteropathogen challenge in mice. J. Gen. Appl. Microbiol., 51(2) 2005, 83-92, .

[2] R.A. França, E.J. Rigo, Utilização de leveduras vivas (Saccharomyces cerevisiae) na nutrição de ruminantes - Uma revisão. FAZU em Revista, 8, 2011, p. 187-195.

[3] M. Thurne, A. Bach, and M. Ruiz-Moreno Effects of Saccharomyces cerevisiae on ruminal pH microbial fermentation in dairy cows yeast supplementation on rumen fermentation. Livestock Science, 124, 2009, p. 261-265.

[4] L.F. Costa, Leveduras na nutrição animal. Revista Eletrônica Nutritime, 1(1), 2004, p.01-06.

[5] F.S. Martins. Utilização de leveduras como probióticos. Revista de Biologia e Ciências da Terra, 5(2), $2005,13-17$.

[6] M. Abadias, A. Benabarre, N. Texidó,J. Usall and I. Vinãs, Effect of freeze drying and protectants on viability of the biocontrol yeast Candida sake. Int. J. Food Microbiol., 65, 2001, p. 173-182.

[7] P.A. Marechal, I. Martinez de Marnañon, I. Poirier and P. Gervais, The importance of the kinetics of application of physical stresses on viability of microrganisms: significance for minimal food processing. Trends Food Sci. Techonol.,10, 1999, 15-20.

[8] E.S. Callaway and S.A. Martin Effects of a Saccharomyces cerevisiae culture on animal bacteria that utilize lactate and digest cellulose. Journal of Dairy Science, 80,1997, 2035- 2044.

[9] J.L. Arcos-Garcia, F.A. Castrejom, G.D. Mendonza and E.P. Perez-Gavilan, Effect of two commercial yeast cultures with Saccharomyces cerevisiae on ruminal fermentation an digestion in sheep fed sugar cane tops. Livestock Production Science, 63, p. $153-157,2000$.

[10] W. Yanbo and X. Zirong Effect of probiotics for common carp (Cyprinus carpio) based on growth performance and digestive enzyme activities. Anim. Feed Sci. Technol., 127, 2006, 283-292.

[11] S. Mohapatra, T. Chakraborty, A.K. Prusty, P. Das, K. Paniprasad and K.N. Mohanta, Use of different microbial probiotics in the diet of rohu, Labeo rohita fingerlings: effects on growth, nutrient digestibility and retention, digestive enzyme activities and intestinal microflora. Aquaculture Nutrition, 18, 2012, 1-11.

[12] M. Abdel-Tawwab, Interactive effects of dietary protein and live bakery yeast, Saccharomyces cerevisiae on growth performance of Nile tilapia, Oreochromis niloticus (L.) fry and their challenge against Aeromonas hydrophila infection. Aquacult Int, 20, 2012, 317-331.

[13] J.Y. Choi, P.L. Shinde, S.L. Ingale, J.S. Kim, Y.W. Kim, I.K. Kwon and B.J. Chae, Evaluation of multi-microbe probiotics prepared by submerged liquid or solid substrate fermentation and antibiotics in weaning pigs. Livestock Science, 138, 2011, 144151. 